\title{
Influence of Pavement Structure, Traffic, and Weather on Urban Flexible Pavement Deterioration
}

\author{
David Llopis-Castelló ${ }^{1, *(1)}$, Tatiana García-Segura ${ }^{2}$ (D) , Laura Montalbán-Domingo ${ }^{2}$, \\ Amalia Sanz-Benlloch ${ }^{2}(\mathbb{D})$ and Eugenio Pellicer ${ }^{2}$ (1) \\ 1 Highway Engineering Research Group, Universitat Politècnica de València, 46022 Valencia, Spain \\ 2 Construction Project Management Research Group, Universitat Politècnica de València, \\ 46022 Valencia, Spain; tagarse@upv.es (T.G.-S.); laumondo@upv.es (L.M.-D.); asanz@upv.es (A.S.-B.); \\ pellicer@upv.es (E.P.) \\ * Correspondence: dallocas@upv.es; Tel.: +34-963877374
}

Received: 29 October 2020; Accepted: 20 November 2020; Published: 21 November 2020

\begin{abstract}
Various studies have been recently conducted to predict pavement condition, but most of them were developed in a certain region where climate conditions were kept constant and/or the research focused on specific road distresses using single parameters. Thus, this research aimed at determining the influence of pavement structure, traffic demand, and climate factors on urban flexible pavement condition over time. To do this, the Structural Number was used as an indicator of the pavement capacity, various traffic and climate variables were defined, and the Pavement Condition Index was used as a surrogate measure of pavement condition. The analysis was focused on the calibration of regression models by using the K-Fold Cross Validation technique. As a result, for a given pavement age, pavement condition worsens as the Equivalent Single Axle Load and the Annual Average Height of Snow increased. Likewise, a cold Annual Average Temperature $\left(5-15^{\circ} \mathrm{C}\right)$ and a large Annual Average Range of Temperature $\left(20-30^{\circ} \mathrm{C}\right)$ encourage a more aggressive pavement deterioration process. By contrast, warm climates with low temperature variations, which are associated with low precipitation, lead to a longer pavement service life. Additionally, a new classification of climate zones was proposed on the basis of the weather influence on pavement deterioration.
\end{abstract}

Keywords: pavement deterioration; pavement surface distress; pavement performance model; pavement structure; weather; traffic

\section{Introduction}

\subsection{Background}

A proper maintenance of road infrastructure is crucial to preserve and enhance social benefits [1,2]. Therefore, the importance of maintenance should be recognized by those competent authorities in decision making, proper funding, and management so as to ensure that maximum value is reached. Keeping an efficient and high-value road network does not only depend on the construction of roads, but also on the correct maintenance of those already built, because they are one of the main assets of the infrastructure of a region or country. A poor or wrong maintenance strategy might cause a significant deterioration of this heritage [3].

For this reason, various highway agencies have developed Pavement Management Systems (PMS) to analyze the life cycle of existing road infrastructures by means of pavement deterioration models [4]. In this regard, many studies have been developed to identify which factors are affecting road deterioration over time [5,6]. Most of these studies were focused on the calibration of pavement deterioration models for interurban roads; therefore, their application to urban pavements might not 
be representative because significant differences exist between both types of pavements regarding road traffic, pavement structure, cross-section, and the influence of distresses on serviceability [7].

In addition, the highway agencies responsible for urban pavements are usually provided by constrained budgets, which results in limited technical resources to collect data about pavement condition; consequently, historic data is scarce. This fact makes difficult the analysis of the deterioration process on urban pavements [8].

Although there is no standard guideline to classify and quantify the different pavement distresses regarding their type, severity, and extension, different researchers and agencies have proposed their own guidelines for their use in a certain region or country [9]. This is the case of the manual included in the Long-Term Pavement Performance (LTPP) program, defined by the Federal Highway Administration (FHWA), which standardizes the data collection about pavement condition and maintenance and rehabilitation (M\&R) activities in the United States and Canada [10]. Likewise, the highway administrations from France and Switzerland have also developed systematic approaches to identify pavement distresses, while the Irish highway administration includes in its road design guideline a pavement surface assessment [6].

The main goal of the above-mentioned guidelines is to provide a set of objective criteria for pavement condition assessment and the definition of management strategies. In fact, most pavement deterioration models use the International Roughness Index (IRI), which is calculated considering a simulated passenger car traveling at $80 \mathrm{~km} / \mathrm{h}$, to describe pavement performance [10-14]. Although the IRI has a good correlation with pavement distresses in interurban pavements [13], this index cannot properly represent pavement condition for urban pavements mainly because of the difficulty of its collection and the low speeds developed in this type of environment [15].

In addition, the use of global performance indicators has demonstrated to be more effective and reliable for pavement condition assessment than a single index $[7,16]$. In this regard, the Pavement Condition Index (PCI) is the most common and used parameter. This index was developed to assess pavement condition in interurban pavements and is calculated as a function of a total of 19 types of pavement distresses, which can be grouped into three categories: (i) surface defects; (ii) surface deformations; and (ii) cracking. Its value ranges between 0 (failed) and 100 (ideal condition).

Osorio et al. [7] proposed the Urban Pavement Condition Index (UPCI) as a surrogate measure of the overall condition of urban pavements and calibrated various regression equations to estimate this index in both flexible and concrete pavements. The UPCI varies from 0 to 10, so that the greater the UPCI, the better the pavement condition. Particularly, the regression equation that estimates this index in flexible pavements depends on the objective assessment of the following distresses: cracking, rutting, patch deterioration, and potholes.

Other performance indexes are the Present Serviceability Index (PSI), which combines the PCI and the Road Condition Index [17], and the Single and Combined Performance Indexes (PIs) defined by the European Cooperation in Science and Technology in the project COST Action 354 [18]. The Singe PIs, which were calibrated in cooperation with 23 European countries and the FHWA, are related to: (i) longitudinal evenness; (ii) transverse evenness; (iii) macro-texture; (iv) friction; (v) bearing capacity; (vi) cracking; and (vii) surface defects. Additionally, various Combined PIs were proposed as the combination of the previous Single PIs to represent important aspects of pavement performance: (i) Safety Index; (ii) Comfort Index; (iii) Structural Index; and (iv) Environmental Index.

The different methods to predict pavement condition can be grouped into the following categories: (i) statistical regression analysis; (ii) artificial neuronal networks; (iii) Bayesian models; and (iv) Markov chains and Monte Carlo simulations [6,19-21]. Although the calibration of regression models requires a great amount of historic data and cannot properly represent the stochastic phenomenon of pavement deterioration over time, regression analysis methods have been widely used because they allow highway engineers to easily predict pavement condition and understand the influence of the parameters included in the model [12,20,22-25]. Moreover, some studies have been recently developed to predict pavement condition considering Markov chains and Monte Carlo simulations [19,23,26-28]. 
The main strength of this method is that it represents the probabilistic pavement deterioration process over time by using a transition probability matrix (TPM) to estimate future pavement condition based on its current state. However, this procedure is not able to distinguish the deterioration process under very different road conditions.

Most previous prediction models were developed for a certain region or country with similar traffic conditions, so these models do not usually incorporate climate factors. This leads to a limited understanding about the influence of weather conditions on pavement deterioration process.

On the other hand, some research concluded that the most influential climate variables on pavement deterioration are temperature and precipitation [10,11,29-31]. Perera and Kohn [10] identified that the IRI experienced greater changes in wet-freeze areas; whereas Madanat et al. [11] pointed out that some of the critical factors affecting the IRI are the temperature of the coldest month and the annual precipitation. In this context, Qiao et al. [29] analyzed the effect of temperature and rainfall on cracking, rutting, and longitudinal evenness. As a result, the pavement deterioration process worsened as the average annual temperature and the temperature difference among seasons increased. Related to this, Mohd Hasan et al. [30] found that longitudinal cracking in flexible pavements was influenced by both temperature and precipitation factors, whereas transverse cracking was only affected by the average annual temperature. In addition, none of these variables had a significant influence on the IRI. Additionally, Anastasopoulos and Mannering [31] concluded that the annual range of temperature and the average annual precipitation were the critical weather factors. However, the effect described by these factors was not consistent because a rise of these variables was not always related to a decrease in the pavement life cycle. This was associated with pavement structure, which might be very different as a function of the region and traffic demand.

Among the few studies that analyzed the global influence of weather and traffic on the pavement deterioration process, Alaswadko and Hassan [32] found that higher traffic loading, lower pavement strength, poor drainage, and climates with high seasonal variation contribute to increasing rutting progression rate.

Therefore, there are some studies focusing on the influence of different pavement factors and traffic levels under similar weather conditions and, conversely, other research studied the influence of weather factors on pavement condition to mainly assess the consequences of climate change. Moreover, most of these studies were based on single performance indexes (e.g., IRI, cracking, rutting or evenness), whereas a global performance index (e.g., PCI) can better represent the underlying phenomenon $[7,16]$.

Additionally, pavement structural capacity has also been associated with pavement condition deterioration process [33]. The Structural Number $(S N)$, which is an indicator of the pavement strength and its structural capacity, is used by many highway agencies in their Pavement Management Information Systems (PMIS) for effective maintenance decisions [34]. In this regard, the greater the SN, the better the pavement condition. However, this parameter has not been studied together with other factors, such as weather and traffic conditions, to assess pavement deterioration process.

\subsection{Objectives}

As previously mentioned, the impact of various factors on pavement deterioration process have been studied in an individual way, i.e., without considering the effect of the other factors. In order to better understand pavement condition evolution, this study aims at analyzing the combined influence of pavement capacity and climate and traffic conditions on pavement deterioration process based on the historic pavement data provided by the Long-Term Pavement Performance (LTPP) program [10]. Particularly, this research is focused on the study of the pavement deterioration process of urban flexible pavements through the Pavement Condition Index, which can better describe the studied phenomenon than a single performance index. For the analysis, the regression technique K-Fold Cross Validation will be applied as this innovative procedure will allow to identify the effect of the proposed variables on pavement deterioration phenomenon. 


\section{Research Method and Data Description}

The research method is displayed in Figure 1, summarizing the dataset, the variables, and the analysis. The study was based on four datasets: (i) pavement distresses; (ii) pavement structure; (iii) traffic demand; and (iv) weather conditions. All these datasets were downloaded for free from the Long-Term Pavement Performance (LTPP) program web site (https:/infopave.fhwa.dot.gov/). The Pavement Condition Index (PCI) of every road section was calculated considering pavement distresses. Likewise, the Structural Number (SN) was estimated using the AASHTO method (AASHTO 1993). Different traffic and climate variables were proposed and estimated for each road section. Finally, the $\mathrm{PCI}$ was analyzed considering pavement age, $S N$, some traffic parameters, and various climate factors as explanatory variables so as to determine the influence of pavement structure, traffic, and weather on pavement deterioration process. To do this, two complementary analysis were proposed: (i) correlation analysis, which allowed the identification of the relationships among the studied variables; and (ii) regression analysis, which was focused on the calibration of regression models to understand and determine the effect of the predictive parameters-pavement structure, traffic, and climate factors-on the performance parameter PCI.

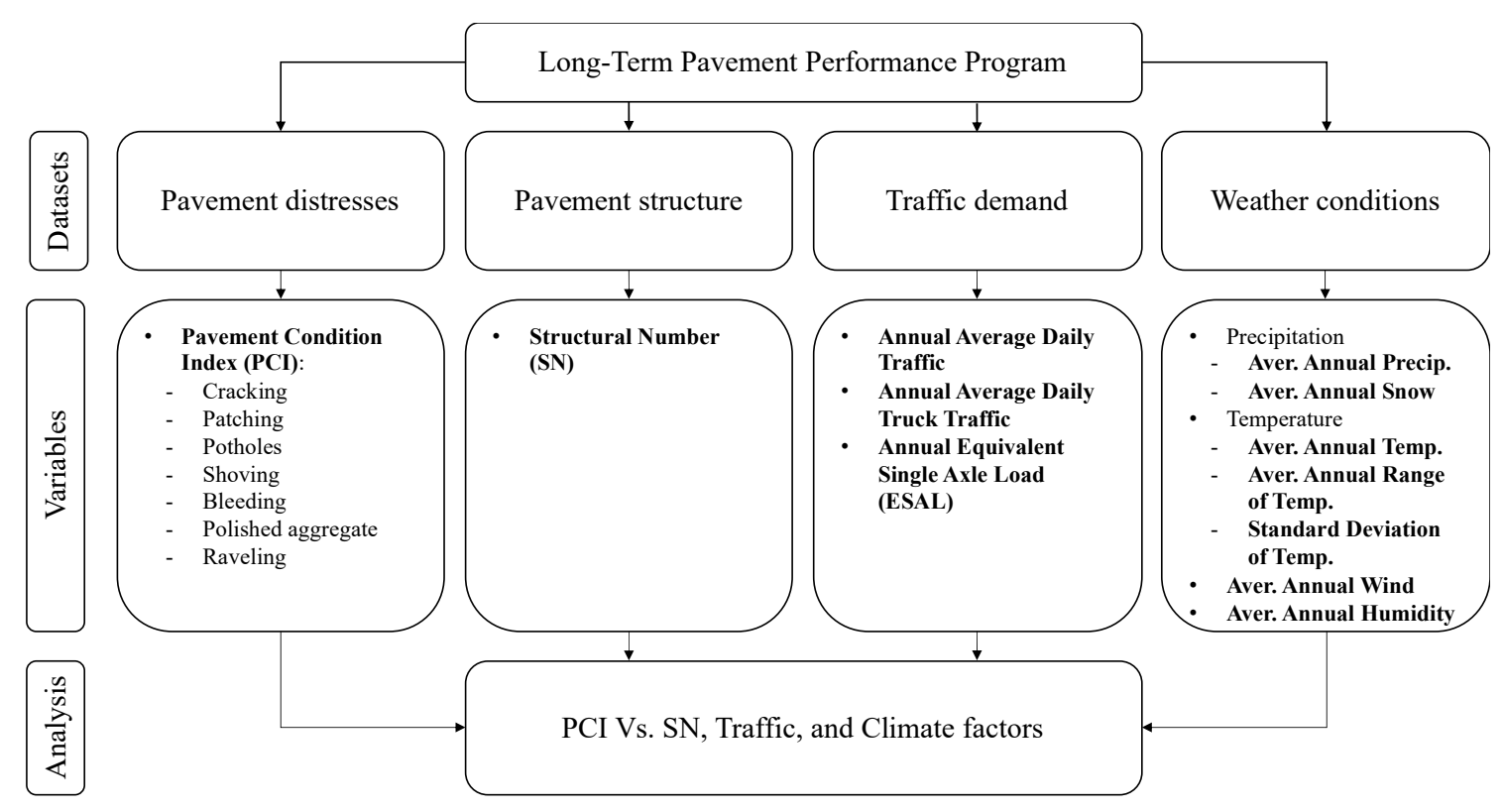

Figure 1. Research method.

\subsection{Road Sections}

The Long-Term Pavement Performance (LTPP) program has been gathering pavement data for approximately 30 years along over 2000 road sections, which are $152 \mathrm{~m}(500 \mathrm{ft})$ long. These data are grouped into the following categories: (i) pavement structure and construction; (ii) pavement performance and distresses; (iii) climate conditions; and (iv) traffic data. Particularly, this study is focused on urban road sections consisting of flexible pavements. Thus, data related to pavement distresses, pavement structure, traffic demands, and weather conditions were downloaded for a total of 53 urban pavements located in the US and Canada. For every road section, a manual survey to identify pavement distresses was carried out, on average, every two years. Besides, traffic demand and weather conditions were available every month. 


\subsection{Pavement Condition}

The Pavement Condition Index (PCI) was considered as a surrogate measure of the level of deterioration of every road segment. This index is based on the following road distresses, which are provided by LTPP:

- $\quad$ Surface Defects

- Ravelling \& Loss of Surface Aggregate

$\bigcirc \quad$ Flushing

- $\quad$ Surface Deformations

- Rippling and Shoving

○ Wheel Track Rutting

D Distortion

- $\quad$ Cracking

$\bigcirc \quad$ Longitudinal Wheel Track Single and Multiple, Alligator

$\bigcirc \quad$ Centerline Single and Multiple, Alligator

○ Pavement Edge Single and Multiple, Alligator

$\bigcirc \quad$ Transverse Single and Multiple, Alligator

L Longitudinal-Meander or Mid-lane

The calculation of the PCI was programmed in Visual Basic, allowing an automated estimation of the PCI for each road section every time the pavement was assessed. Nevertheless, only PCI values until the first maintenance and rehabilitation (M\&R) activity were considered in the analysis because the pavement performance and capacity might significantly change depending on the type of the implemented R\&M activity.

Therefore, a specific road section can have several PCI values corresponding with each pavement assessment. In this way, each PCI estimation is associated with a certain pavement age $\left(p_{a}\right)$, which is calculated as the difference between the date of the pavement assessment and the date of its construction. After this data reduction, a total of 234 pavement assessments, which were carried out in 50 road sections located in 17 states, were considered to analyze the influence of traffic and climate factors on pavement condition.

\subsection{Pavement Structure}

The Structural Number $(S N)$ of a pavement is a numerical value that indicates pavement strength and capacity. In this way, pavement structural capacity is greater as $S N$ increases. According to the AASHTO method [35], this parameter is estimated by Equation (1).

$$
S N=a_{1} \cdot D_{1}+a_{2} \cdot D_{2} \cdot m_{2}+a_{3} \cdot D_{3} \cdot m_{3}
$$

where $S N$ is the structural number (in); $a_{1}, a_{2}$, and $a_{3}$ are the structural layer coefficient of the Asphalt Concrete (AC), base, and subbase layers, respectively; $D_{1}, D_{2}$, and $D_{3}$ are the thickness of the Asphalt Concrete (AC), base, and subbase layers, respectively (in); and $m_{2}$ and $m_{3}$ are the drainage coefficient of the base and subbase layers, respectively.

The structural layer coefficients $\left(a_{i}\right)$ are obtained from the resilient modulus of each layer, which are provided by the LTPP program. Likewise, the thickness of every layer is also available. However, the drainage coefficients are unknown and assumed to be 1 for this research.

Thus, the $S N$ was calculated for every road section after road construction. The maximum and minimum values of this parameter are 12.02 in and 2.64 in, respectively. Likewise, the mean value is $6.55 \mathrm{in}$ and its standard deviation is $2.39 \mathrm{in}$. 


\subsection{Traffic and Climate Variables}

As previous research concluded, one of the most influential factors on pavement deterioration is traffic load $[21,32,36,37]$. Regarding this, the following traffic variables were considered in this research:

- Annual Average Daily Traffic (AADT) in vehicles per day (vpd).

- Annual Average Daily Truck Traffic (AADTT) in vpd.

- Equivalent Single Axle Load (ESAL) in thousands (KESAL).

The annual values of these variables were directly provided by the LTPP program and were estimated for each pavement assessment as the average values from the date of the pavement construction to the date of the current pavement assessment $\left(p_{a}\right)$.

Although most previous studies found that precipitation and temperature are the most influential climate factors on pavement condition, this research also analyzed other climate factors such as wind and humidity. Thus, the following climate variables were proposed:

- Annual Average Precipitation (AAP) in $\mathrm{mm}$, calculated as the average annual rain precipitation $(\mathrm{mm})$ during pavement age $\left(p_{a}\right)$.

- Annual Average Height of Snow (AAS), estimated as the average annual snow precipitation (mm) during $p_{a}$.

- Annual Average Temperature (AAT), obtained as the average annual air temperature $\left({ }^{\circ} \mathrm{C}\right)$ during $p_{a}$.

- Annual Average Range of Temperature (AART), estimated as the average of the annual range of air temperature $\left({ }^{\circ} \mathrm{C}\right)$, calculated for each year as the temperature difference between the coldest and warmest month-during $p_{a}$.

- Standard Deviation of Temperature (SDT), calculated as the standard deviation of the air temperature $\left({ }^{\circ} \mathrm{C}\right)$ during $p_{a}$.

- Annual Average Wind (W), obtained as the annual average wind speed $(\mathrm{km} / \mathrm{h})$ during $p_{a}$.

- Annual Average Humidity (H), estimated as the annual average humidity (\%) during $p_{a}$.

In this way, each pavement assessment was associated with a specific pavement age, traffic conditions, and climate factors. Table 1 shows a statistical summary of these variables for the 237 pavement assessments performed in the studied urban road sections.

Table 1. Traffic and weather conditions of the studied road sections.

\begin{tabular}{ccccccc}
\hline Variable & Average & $\begin{array}{c}\text { Standard } \\
\text { Deviation }\end{array}$ & $\begin{array}{c}\text { Coefficient } \\
\text { of Variation }\end{array}$ & Minimum & Maximum & Range \\
\hline AADT $(\mathrm{vpd})$ & 5436.87 & 4894.40 & 0.90 & 1628 & 24,222 & 22,594 \\
AADTT (vpd) & 633.13 & 561.00 & 0.89 & 105 & 3089 & 2984 \\
KESAL & 282.90 & 208.67 & 0.74 & 16 & 1988 & 1972 \\
AAP $(\mathrm{mm})$ & 871.53 & 368.32 & 0.42 & 228.90 & 2030.20 & 1801.30 \\
AAS $(\mathrm{mm})$ & 851.73 & 715.47 & 0.84 & 0.00 & 3564.85 & 3564.85 \\
AAT $\left({ }^{\circ} \mathrm{C}\right)$ & 9.90 & 6.85 & 0.69 & 0.00 & 24.17 & 24.17 \\
AART $\left({ }^{\circ} \mathrm{C}\right)$ & 27.22 & 8.68 & 0.32 & 4.08 & 41.20 & 37.12 \\
SDT $\left({ }^{\circ} \mathrm{C}\right)$ & 9.50 & 2.96 & 0.31 & 1.45 & 14.71 & 13.26 \\
$\mathrm{~W}(\mathrm{~km} / \mathrm{h})$ & 13.40 & 2.81 & 0.21 & 6.62 & 23.34 & 16.72 \\
$\mathrm{H}(\%)$ & 71.27 & 3.09 & 0.04 & 56.90 & 76.00 & 19.10 \\
\hline
\end{tabular}

\subsection{Model Calibration}

The models calibrated in this research were developed by using the K-Fold Cross Validation technique $[25,38]$. This technique results in a less biased model compared to a conventional regression technique that usually splits data into training and test sets. Specifically, K-Folds Cross Validation splits the entire dataset randomly into $k$ folds. Then, the method fit a model using $k-1$ folds and validates the model using the remaining $k t h$ fold. This process is repeated until every $k$-fold serves as 
the test set. As a result, the technique provides the average of both the coefficients of the model and the parameter used as a measure the goodness of fit, estimated from test sets.

The selection of $k$ is critical when using this technique. A high value of $k$ leads to less biased model, but large variance might lead to overfit, whereas a low value of $k$ is similar to the train-test split approach used in a conventional regression. In other words, the value of $k$ should not be too small or too high, being recommended to use a value of 10 [39]. Therefore, the dataset of this research was divided into ten folds. In this way, a total of 10 sub-models were developed to calibrate a unique model (Figure 2). The equations presented in the following sections show the average values of the regression coefficients, estimated from training sets, and the coefficient of determination, calculated from test sets.

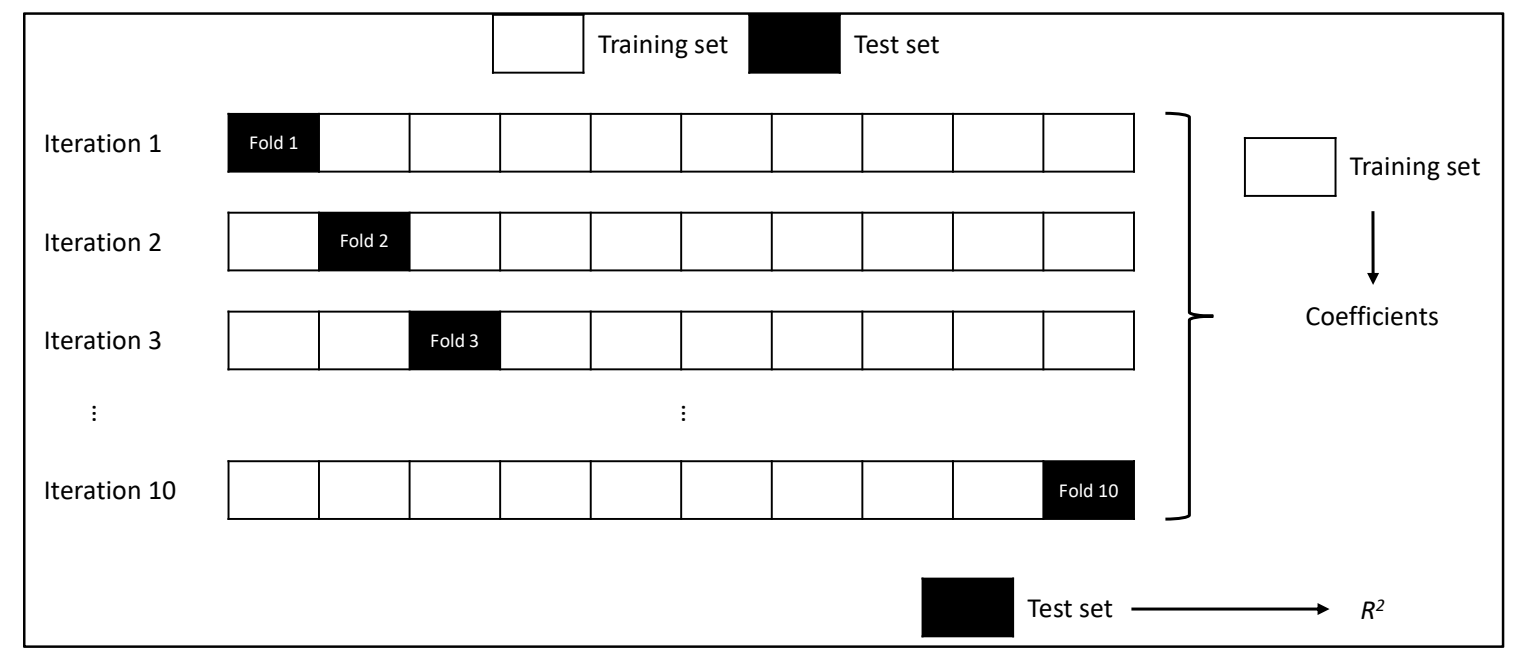

Figure 2. K-Fold Cross Validation technique.

It is important to note that the main objective of the model calibration is to understand the phenomenon, i.e., the identification of the most influential variables in pavement deterioration. To do this, first, each group of variables is analyzed separately and, finally, global regression models are calibrated by applying the forward stepwise regression technique. All models have been calibrated in Python, using the scikit-learn library.

\section{Analysis and Results}

First, a correlation analysis was carried out to identify the relationship between the studied variables. The Pearson correlation factor $(r)$ for each combination of variables is shown in Table 2. Shading represents the level of correlation between two variables from non-shaded $(|r|<0.4)$, medium $(0.4<|r|<0.7))$ to dark $(|r|>0.7)$.

Table 2. Correlation matrix.

\begin{tabular}{|c|c|c|c|c|c|c|c|c|c|c|c|c|c|}
\hline & PCI & $p_{a}$ & $A A D T$ & $A A D T T$ & KESAL & $A A P$ & $A A S$ & $A A T$ & $A A R T$ & $A D T$ & $W$ & $H$ & $S N$ \\
\hline PCI & & -0.7079 & -0.2252 & -0.2012 & -0.1399 & -0.0809 & -0.1784 & -0.0601 & 0.0810 & 0.0739 & -0.0496 & 0.2374 & 0.1062 \\
\hline$p_{a}$ & -0.7079 & & 0.1116 & -0.0152 & -0.0983 & 0.1442 & -0.1095 & 0.3163 & -0.3082 & -0.3159 & 0.2530 & -0.2251 & -0.0757 \\
\hline$A A D T$ & -0.2252 & 0.1116 & & & 0.2746 & & -0.1732 & 0.4312 & -0.3977 & & -0.1353 & -0.1291 & 0.0583 \\
\hline$\overline{A A D T T}$ & -0.2012 & -0.0152 & 0.7430 & & 0.7216 & 0.2753 & -0.0422 & 0.1018 & -0.0885 & -0.0717 & -0.3970 & -0.0492 & -0.0518 \\
\hline KESAL & -0.1399 & -0.0983 & 0.2746 & 0.7216 & & -0.1438 & 0.1314 & -0.3718 & 0.3840 & 0.3897 & -0.3454 & 0.1905 & -0.3107 \\
\hline$\overline{A A P}$ & -0.0809 & 0.1442 & 0.3589 & 0.2753 & -0.1438 & & $\overline{494}$ & 0.5377 & -0.4327 & -0.4203 & -0.2831 & -0.0920 & 0.2018 \\
\hline$A A S$ & -0.1784 & -0.1095 & -0.1732 & -0.0422 & 0.1314 & -0.2494 & & -0.6202 & 0.4866 & 0.4997 & -0.2371 & 0.3349 & 0.1323 \\
\hline$A A T$ & -0.0601 & 0.3163 & 0.4312 & & -0.3718 & 0.5377 & -0.6202 & & -0.9317 & -0.9356 & 0.22 & -0.3476 & 0.10 \\
\hline AART & 0.0810 & -0.3082 & -0.3977 & .0885 & 0.3840 & -0.4327 & 0.4866 & -0.9317 & & 0.9977 & -0.3006 & 0.2212 & -0.2032 \\
\hline$A D T$ & 0.0739 & -0.3159 & -0.3840 & -0.0717 & 0.3897 & -0.4203 & 0.4997 & -0.9356 & 0.9977 & & -0.3212 & 0.2165 & -0.1907 \\
\hline$W$ & -0.0496 & 0.2530 & -0.1353 & -0.3970 & -0.3454 & -0.2831 & -0.2371 & 0.2273 & -0.3006 & -0.3212 & & -0.2440 & -0.0671 \\
\hline$H$ & 0.2374 & -0.2251 & -0.1291 & -0.0492 & 0.1905 & -0.0920 & 0.3349 & -0.3476 & 0.2212 & 0.2165 & -0.2440 & & 0.0199 \\
\hline$S N$ & 0.1062 & -0.0757 & 0.0583 & -0.0518 & -0.3107 & 0.2018 & 0.1323 & 0.1026 & -0.2032 & -0.1907 & -0.0671 & 0.0199 & \\
\hline
\end{tabular}


As expected, the dependent variable, PCI, was closely related to pavement age $\left(p_{a}\right)$, so that pavement condition worsens as $p_{a}$ increases. Annual traffic conditions (AADT, AADTT, and KESAL) show a weak relationship with pavement condition. Particularly, $A A D T$ and $A A D T T$ had a slightly stronger relationship with PCI than KESAL. Moreover, a close relationship between these variables was found. The coefficients of correlation between AADT and AADTT, and between AADTT and KESAL were over 0.7 .

Although a high correlation between $S N$ and traffic conditions was expected because the pavement is designed to support traffic load, these variables did not present a significant correlation. Only KESAL showed a slight correlation $(-0.3107)$ with $S N$.

Regarding the climate factors, it should be noted that the variables related to precipitation (AAP and $A A S$ ) described a moderate relationship with those associated with temperature (AAT, AART, and $S D T)$. In addition, a strong relationship was found among the three temperature variables. Finally, $W$ and $H$ showed a weak relationship with the other climate factors.

A deeper analysis focused on the study of the influence of each variable on pavement deterioration is presented in the following sections. Regarding this, although different model forms were tested, only the most accurate models are included.

\subsection{Influence of Pavement Age}

The main factor in pavement deterioration process, which is considered a stochastic phenomenon, was pavement age $\left(p_{a}\right)$. Although this study considered road sections characterized by very different traffic and climate conditions, $p_{a}$ was able to represent the pavement deterioration process properly. The relationship between PCI and $p_{a}$ was modeled through Equation (2) that describes a linear decrease of PCI over time; Figure 3 plots the data. Specifically, the PCI of a road section decreases approximately 5 units per year from the first year and a half of its construction.

$$
\left\{\begin{array}{ll}
P C I=100 & \text { if } p_{a}<2 \\
P C I=111.01-5.46 \cdot p_{a} & \text { if } p_{a} \geq 2
\end{array} \quad R_{\text {test }}^{2}=0.48\right.
$$

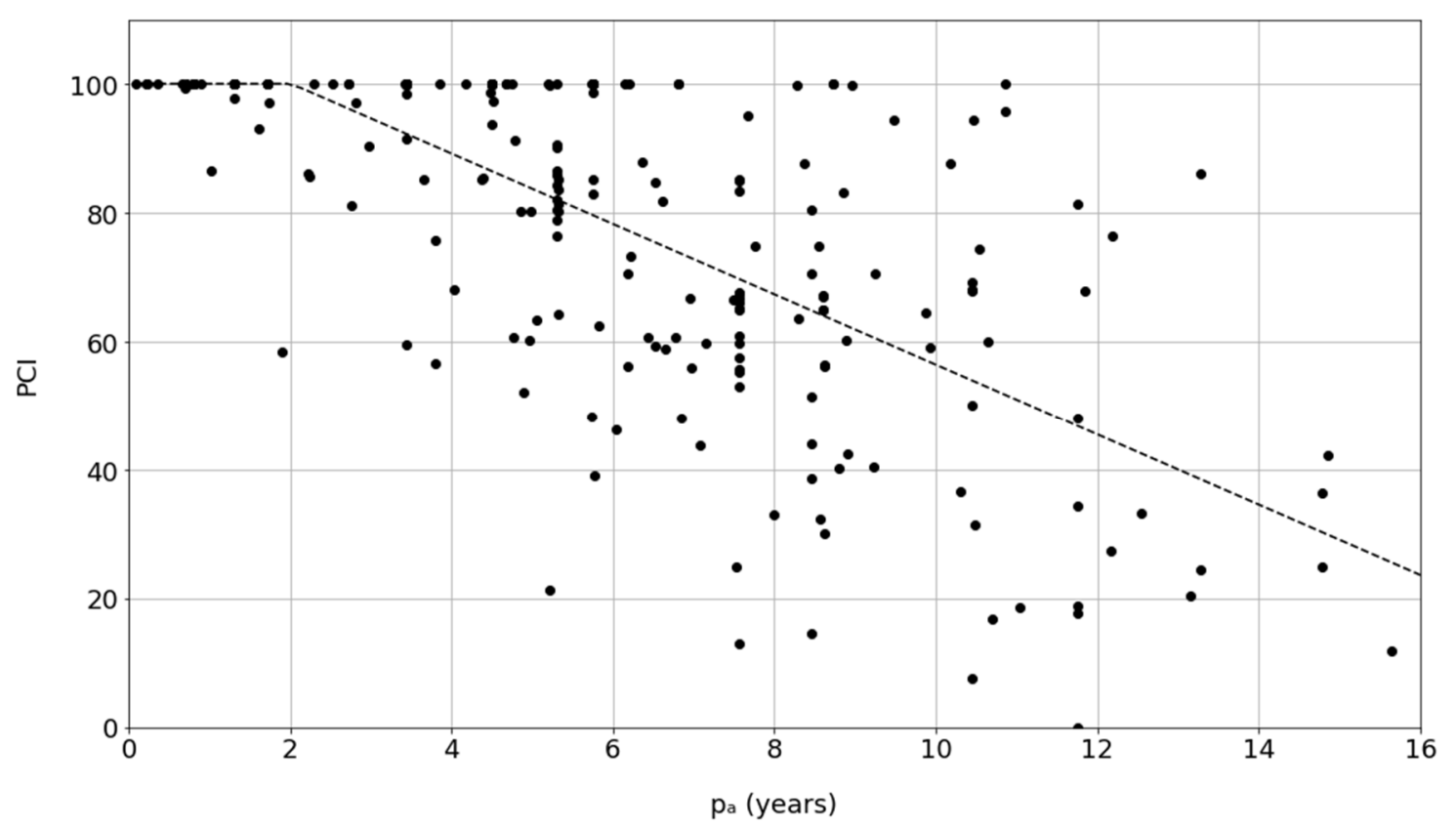

Figure 3. Influence of pavement age on pavement deterioration.

T calibrated model was constrained with a maximum value of 100 and a minimum value of 0 according to the definition of the PCI. In this way, a 0.48 coefficient of determination was reached, 
meaning that pavement age $\left(p_{a}\right)$ is able to explain up to half of the variability of the phenomenon and, therefore, plays a critical role in pavement deterioration process.

\subsection{Influence of Pavement Structure}

The influence of pavement capacity is studied from the Structural Number (SN). As discussed previously, this parameter did not show correlation with the PCI and traffic loads. To determine the impact of the pavement structure on pavement deterioration process, the residuals of the previous model (Equation (2)) were studied considering SN (Figure 4). This analysis showed that pavement capacity does not have a significant impact on the studied phenomenon because the residuals are homoscedastic and approximately rectangular-shaped.

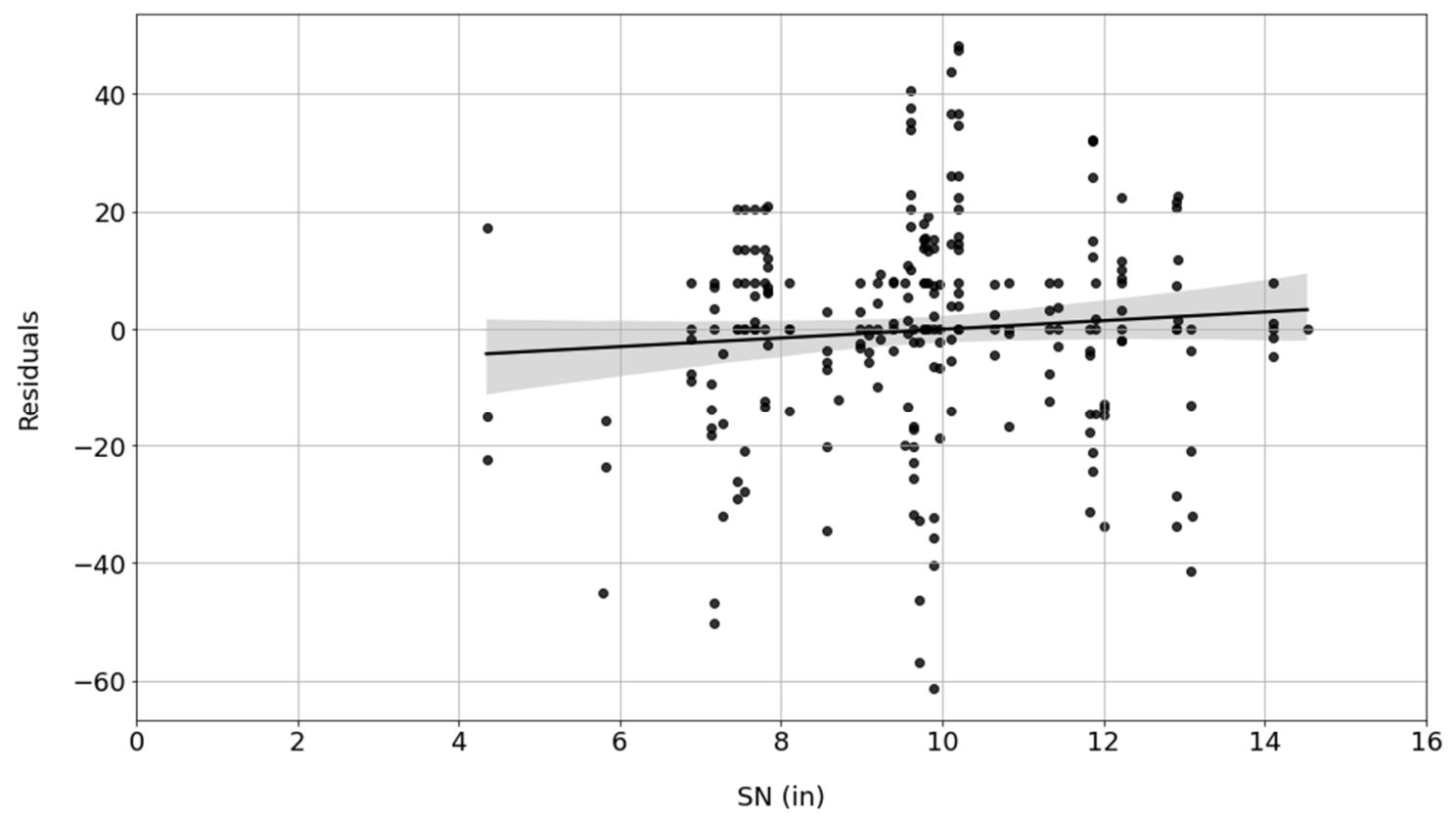

Figure 4. Residuals from Equation (2) vs. structural number.

However, for values of $S N$ greater than 10 in, the residuals tend to be positive. This means that the predicted PCI for those pavements with a high structural capacity is underestimated. By contrast, the predicted PCI is overestimated for those pavements with values of $S N$ lower than $10 \mathrm{in}$. Although further research is needed to obtain firm conclusions, these results suggest that those road sections characterized by a high value of $S N$ delay the pavement deterioration process.

Equation (3) shows the model calibrated to predict PCI from pavement age $\left(p_{a}\right)$ and $S N$. As expected, this model does not enhance the reliability of the prediction obtained in Equation (2) since the adjusted coefficient of determination have not substantially increased. In this regard, pavement structure is only able to explain approximately $1 \%$ of the variability.

$$
P C I=99.44-5.54 \cdot p_{a}+1.27 \cdot S N \quad R_{\text {test }}^{2}=0.49
$$

Figure 5 represents the calibrated model that properly describes the above-mentioned trend. In this graphic, the level of PCI is shown as a function of pavement age and structure. For a specific pavement age, pavement condition increases as $S N$ is higher. 


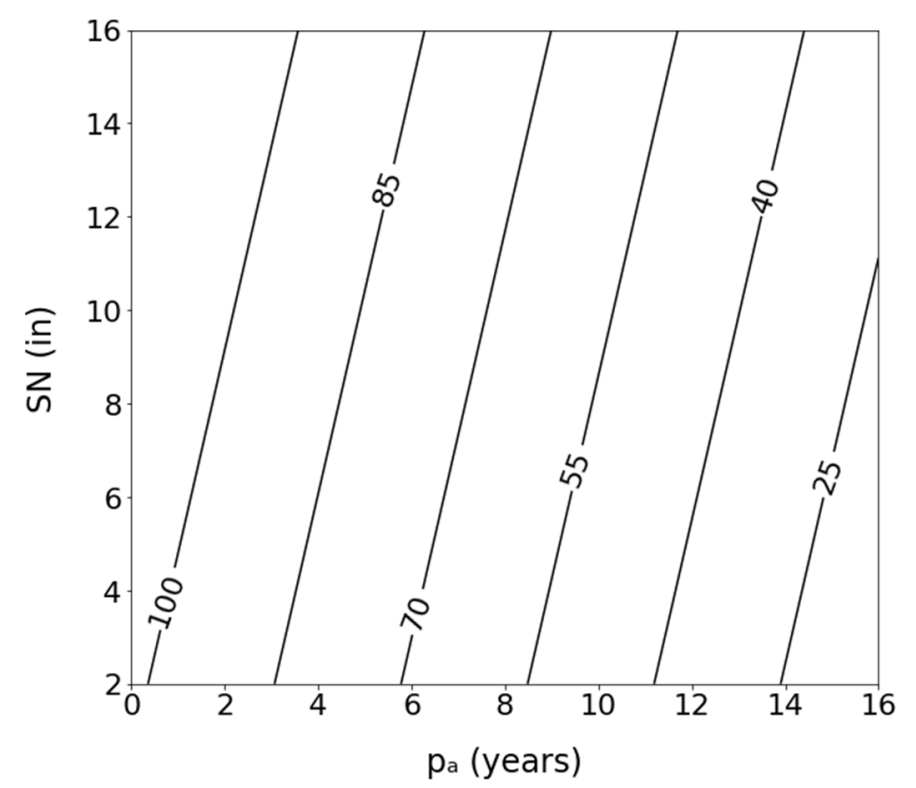

Figure 5. Influence of pavement age and pavement structure on pavement deterioration.

These findings might be influenced by the index used for pavement condition assessment and the action plan, i.e., when a pavement must be rehabilitated. Although the PCI includes pavement distresses related to structural failures, the pavement assessment is superficial, so not all the structural distresses are considered. Additionally, a road is rehabilitated before suffering important structural fails so as to avoid its reconstruction. Thus, pavement maintenance might be more associated with superficial fails than structural ones.

Related to this, another important variable that might be crucial in the analysis of the impact of the pavement structure on pavement deterioration is the subgrade bearing capacity. To this regard, the main hypothesis is that a faster pavement deterioration is expected as the bearing capacity decreases.

\subsection{Influence of Traffic Load}

This research proposed three traffic variables: AADT, AADTT, and KESAL. As shown in Table 2, these variables presented moderate and strong positive correlations among them, so the influence of all of them on pavement deterioration could be considered similar. To identify this influence, the residuals of the model described in Equation (2) were studied as a function of the traffic variables. As a result, $A A D T T$ and KESAL showed a greater influence than $A A D T$, so heavy vehicles play a crucial role in pavement deterioration process.

Particularly, KESAL, which is used by the AASTHO for designing pavement layers, resulted in the most influential traffic factor. Thus, a combined model was calibrated considering this variable together with pavement age (Equation (4)). This model describes a reduction in PCI as KESAL increases, i.e., pavement condition worsens as heavy traffic takes on importance; this is shown in Figure 6.

$$
P C I=121.96-5.80 \cdot p_{a}-0.0296 \cdot K E S A L \quad R_{\text {test }}^{2}=0.55
$$




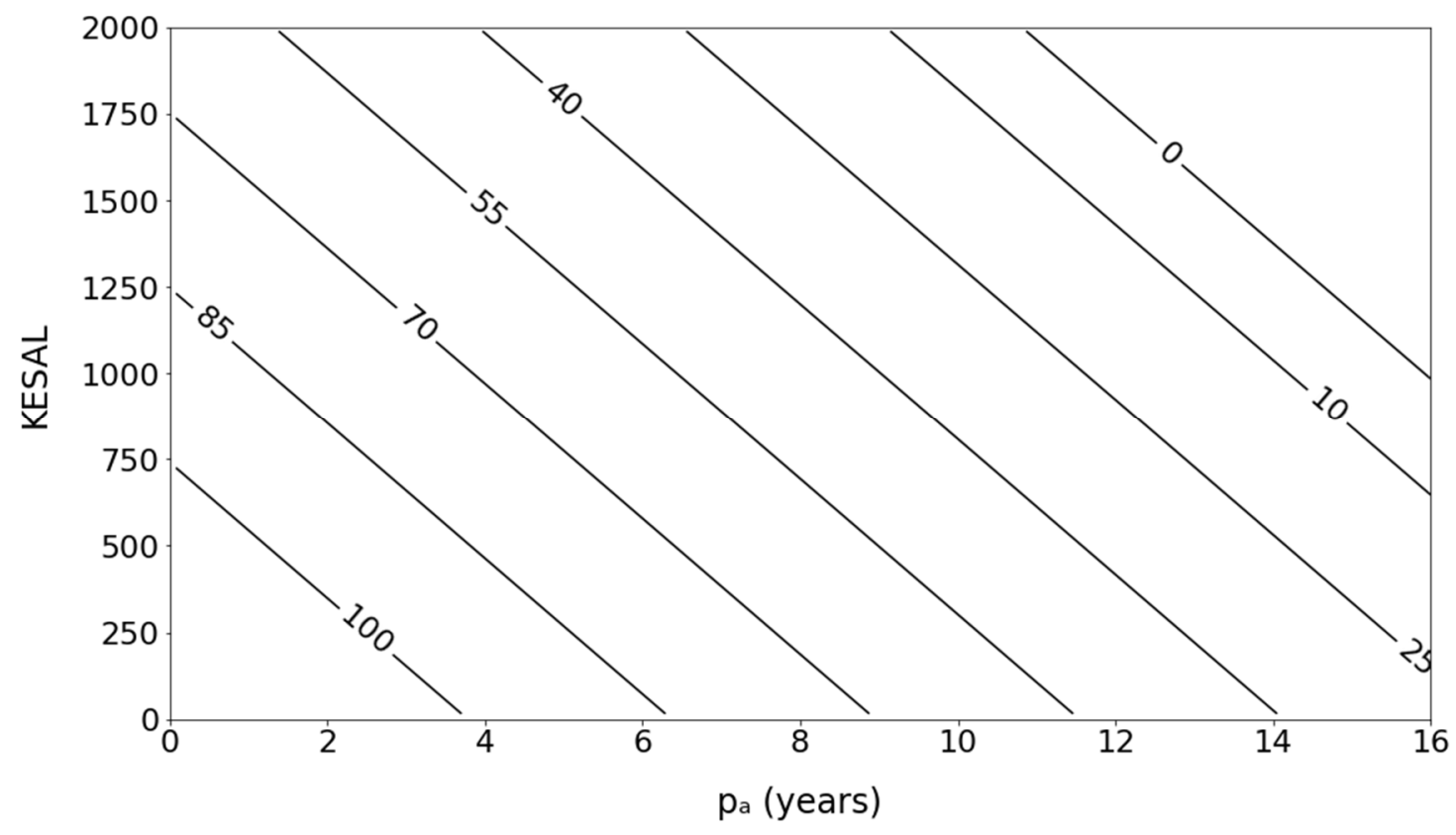

Figure 6. Influence of traffic load on pavement deterioration.

As can be observed, the inclusion of traffic load in the regression analysis significantly rose the accuracy of the model. Particularly, the variable KESAL accounts for $7 \%$ of the variability of the phenomenon, which means a great contribution in pavement deterioration process.

\subsection{Influence of Climate Conditions}

The influence of precipitation, temperature, wind, and humidity on pavement deterioration process was analyzed considering the weather variables shown in Table 1. To do this, the residuals of the base model that only includes pavement age as explanatory variable (Equation (2)) were studied as a function of each climate factor. As a result, the most influential variables were those related to precipitation and temperature. Regarding precipitation variables, the Annual Average Height of Snow $(A A S)$ had a greater impact on pavement condition than the Annual Average Precipitation $(A A P)$, which resulted in a non-significant variable $(P$-value $=0.8980)$. Specifically, given a certain pavement age, PCI decreases 1 unit per $100 \mathrm{~mm}$ of snow (see Equation (5) and Figure 7a).

$$
P C I=122.43-5.79 \cdot p_{a}-0.0108 \cdot A A S \quad R_{\text {test }}^{2}=0.54
$$




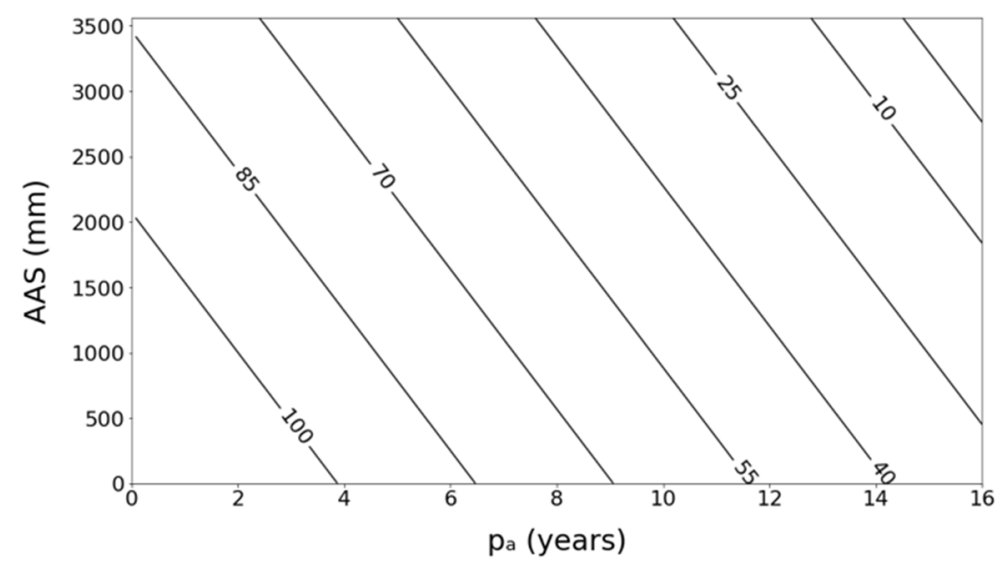

(a)

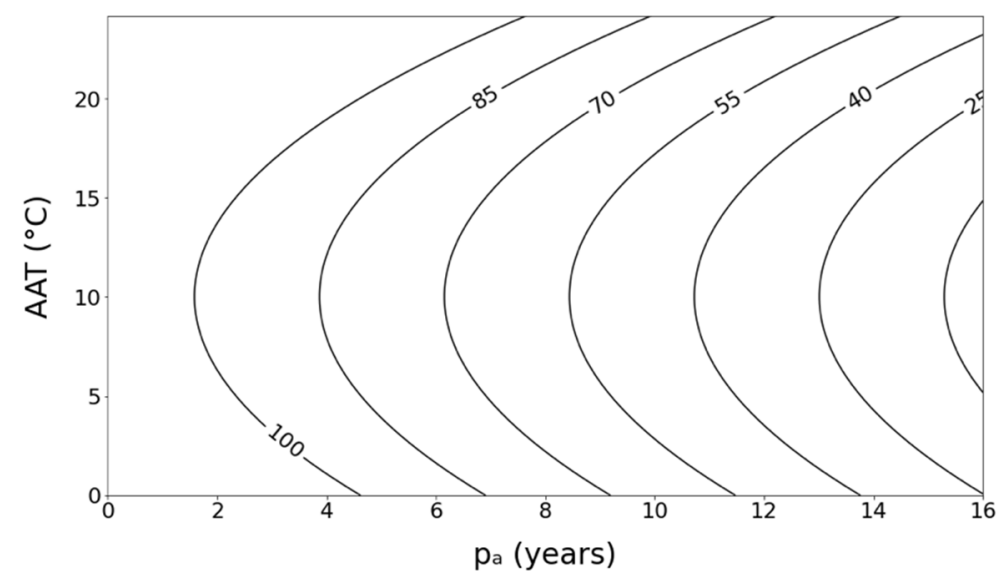

(b)

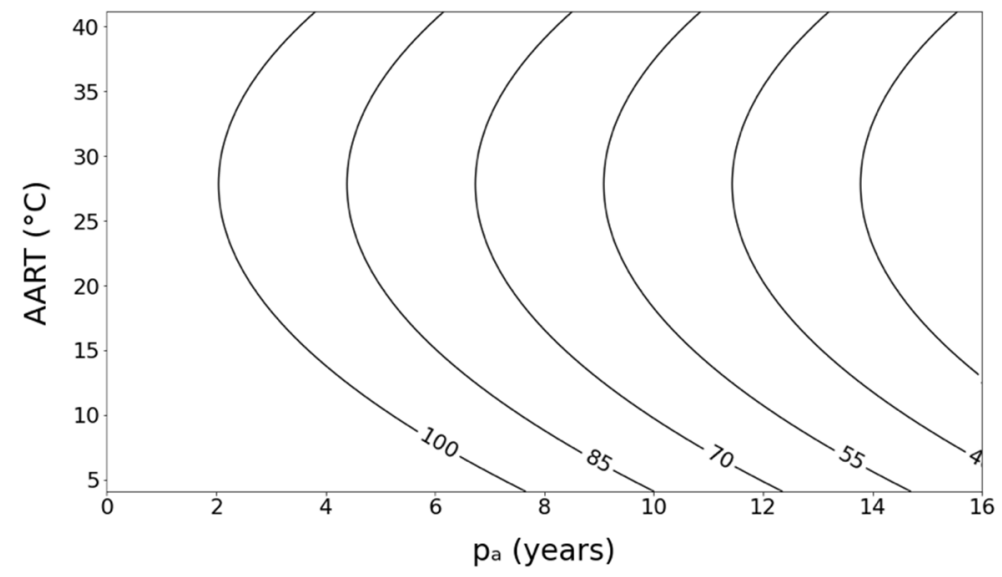

(c)

Figure 7. Individual influence of climate conditions on pavement deterioration: (a) Annual Average Snow; (b) Annual Average Temperature; (c) Annual Average Range of Temperature.

The Annual Average Temperature $(A A T)$ showed the strongest relationship with the studied phenomenon concerning the analyzed temperature variables. This relationship was modeled through Equation (6) and represented in Figure 7b. Unlike pavement capacity, traffic load, and precipitation that presented a linear relationship with pavement condition, the Annual Average Temperature showed a parabolic effect. In this way, pavements exposed to annual average temperatures between 5 and 
$15{ }^{\circ} \mathrm{C}$ experienced a sudden deterioration process. In addition, pavements located in warm regions $\left(A A T=20-30^{\circ} \mathrm{C}\right)$ showed a substantial delay in the beginning of the deterioration process.

On the other hand, those variables that represent temperature variation, $A A R T$ and $S D T$, described the same trend (see Equation (7) and Figure 7c). As expected, the beginning of the pavement deterioration process was significantly delayed as the temperature variation during the year decreases.

Therefore, the inclusion of climatic factors in pavement condition assessment led to a more accurate estimation of the PCI and a better understanding of the phenomenon. Specifically, the impact of weather conditions on pavement deterioration process resulted in an increase in the explained variability between $7 \%$ and $8 \%$. Due to the parabolic relationship between temperature variables ( $A A T$ and $A A R T$ ) and pavement condition, the 3D representation of Equations (6) and (7) would be a parabolic surface whose projection in a 2D graphic results in parabolic contour lines (Figure $7 \mathrm{~b}, \mathrm{c}$ ).

$$
\begin{array}{cc}
P C I=130.36-6.56 \cdot p_{a}-3.98 \cdot A A T+0.1988 \cdot A A T^{2} & R_{\text {test }}^{2}=0.55 \\
P C I=162.33-6.39 \cdot p_{a}-3.54 \cdot A A R T+0.0636 \cdot A A R T^{2} & R_{\text {test }}^{2}=0.56
\end{array}
$$

Finally, a regression model that globally represents the influence of climate factors on pavement deterioration process was calibrated. Given that both Annual Average Wind Speed $(W)$ and Annual Average Humidity $(H)$ did not have a statistical significance influence on pavement condition for the studied road sections, these variables were not taking into account in the model. In addition, the correlation between $A A S$ and $A A T$ was stronger than that obtained for $A A S$ and $A A R T$ (see Table 2), so these latest variables together with pavement age were considered in the model calibration. Equation (8) and Figure 8 summarizes the global relationship between climate conditions and pavement deterioration over time.

$$
P C I=152.75-6.17 \cdot p_{a}-0.0091 \cdot A A S-2.76 \cdot A A R T+0.0570 \cdot A A R T^{2} \quad R_{\text {test }}^{2}=0.58
$$
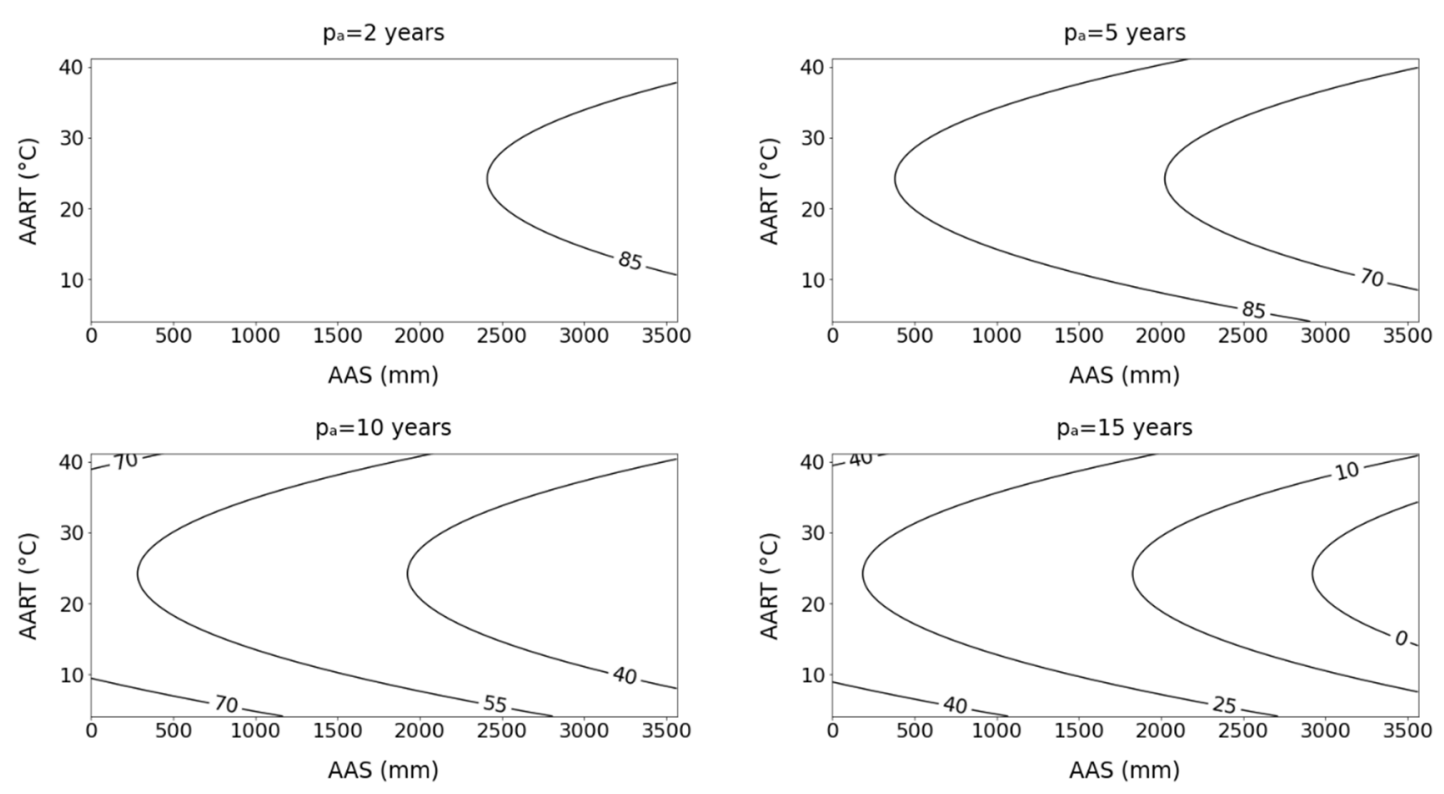

Figure 8. Global influence of climate conditions on pavement deterioration. 
Despite the slight enhancement in model accuracy, relevant conclusions were found. Those pavement sections with temperature variations between $20^{\circ} \mathrm{C}$ and $30^{\circ} \mathrm{C}$ started their deterioration process earlier than those with low or extreme temperature variations. This might be explained by the fact that pavements with the previously mentioned temperature variations are more prone to suffer numerous freeze and thaw cycles, which negatively affects their condition.

In this regard, temperature variations between $20^{\circ} \mathrm{C}$ and $30^{\circ} \mathrm{C}$ were associated with pavement sections with an Annual Average Temperature $(A A T)$ ranged from $5{ }^{\circ} \mathrm{C}$ to $15^{\circ} \mathrm{C}$, which encouraged loads of freeze and thaw cycles, whereas pavements with extreme temperature variations $\left(>30^{\circ} \mathrm{C}\right)$ were related to an $A A T$ lower than $3{ }^{\circ} \mathrm{C}$, which led to a lower number of freeze and thaw cycles delaying the deterioration process.

Additionally, for a given $A A R T$ value, pavement condition worsened as the height of the snow increased.

\subsection{Global Influence}

Once pavement structure, traffic demand, and climate conditions were individually studied, a global analysis was developed to determine the combined influence of traffic and weather on pavement condition. To do this, different regression models were calibrated combining the proposed traffic variables (AADT, AADTT, and KESAL) with the most influential climate factors (AAS, AAT, and AART), without considering $S N$ due to its low impact on pavement deterioration process (Equations (9), (10), and (11)). Although these models provided a slight increase in accuracy ( $\left.R_{\text {test }}^{2}\right)$ compared to the individual models, interesting global conclusions were obtained that supported the findings described previously. These models pointed out that pavement condition decreases over 6 units per year and around 2 units per 100,000 Equivalent Single Axle Load. Likewise, for a given pavement age and traffic conditions, the higher the annual snow precipitation, the lower the pavement condition (see Figure 9a). Regarding temperature variables, a sudden pavement deterioration was related to cold temperatures $\left(5-15^{\circ} \mathrm{C}\right)$ and high annual temperature variations $\left(20-30^{\circ} \mathrm{C}\right)$ (see Figure $9 \mathrm{~b}, \mathrm{c}$ ). Additionally, an important delay in the deterioration process was found in those pavement sections located in warm climates with low temperature variations, which in turn were usually characterized by low rainfall.

$$
\begin{gathered}
P C I=132.57-6.14 \cdot p_{a}-0.0265 \cdot \mathrm{KESAL}-0.0104 \cdot \mathrm{AAS} \quad R_{\text {test }}^{2}=0.59 \\
P C I=137.43-6.60 \cdot p_{a}-0.0196 \cdot \mathrm{KESAL}-3.89 \cdot \mathrm{AAT}+0.1847 \cdot \mathrm{AAT}^{2} \quad R_{\text {test }}^{2}=0.59 \\
P C I=163.04-6.47 \cdot p_{a}-0.0239 \cdot \mathrm{KESAL}-3.22 \cdot A A R T+0.0615 \cdot A A R T^{2} \quad R_{\text {test }}^{2}=0.58
\end{gathered}
$$

Summarizing, the combination of traffic and weather variables together with pavement age in pavement condition assessment enabled a better understanding of the pavement deterioration process. As previously mentioned, the main factor affecting on pavement deterioration was pavement age. However, both traffic demand and weather conditions, specifically precipitation and temperature, also resulted in key factors. In this regard, the combinations of these three factors substantially rose the determination coefficient considering test sets (see Equations (9)-(11)). 

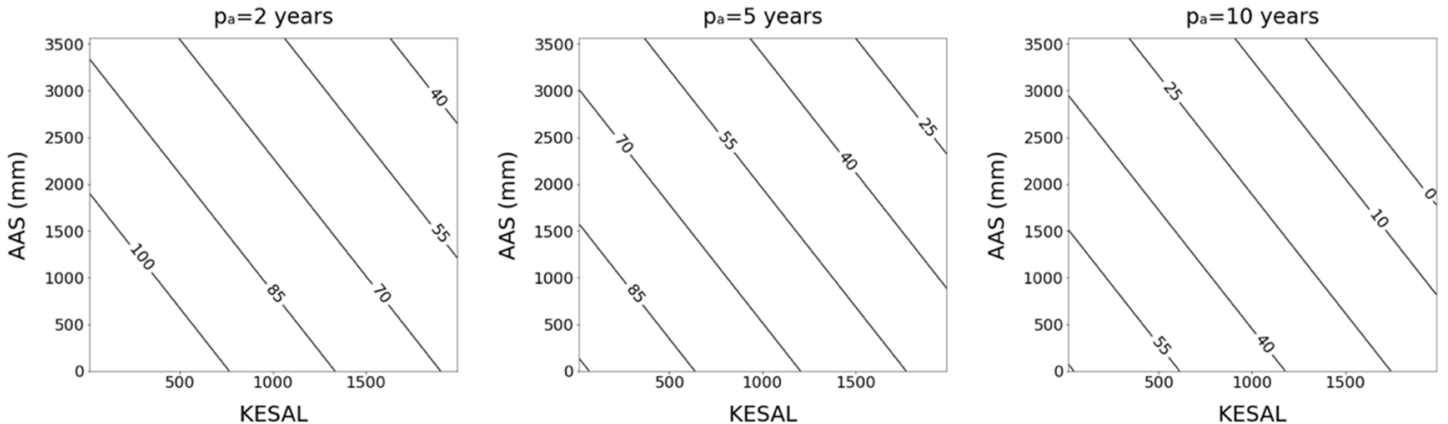

(a)
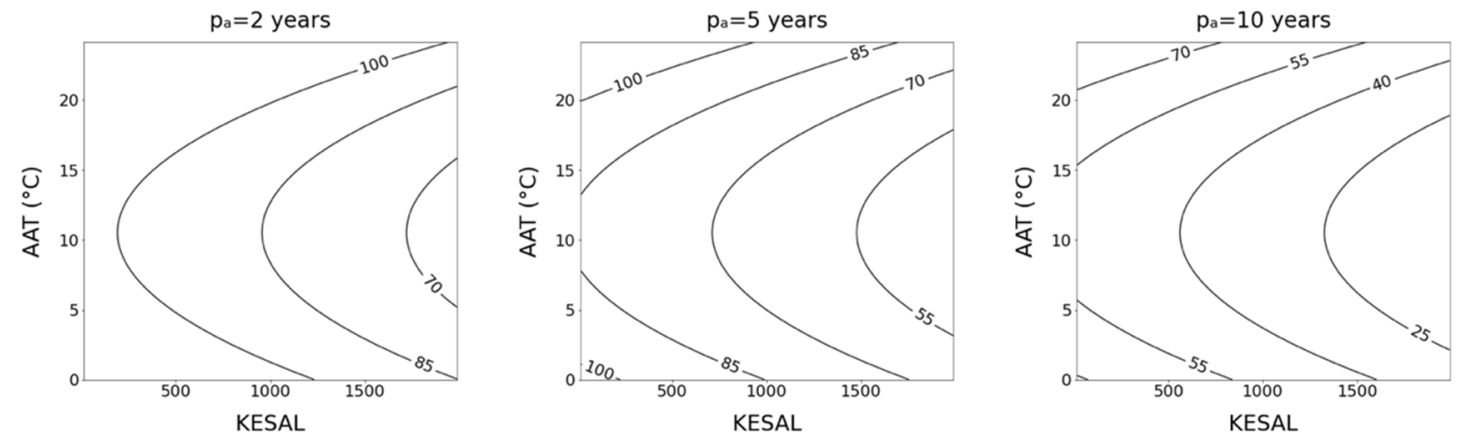

(b)
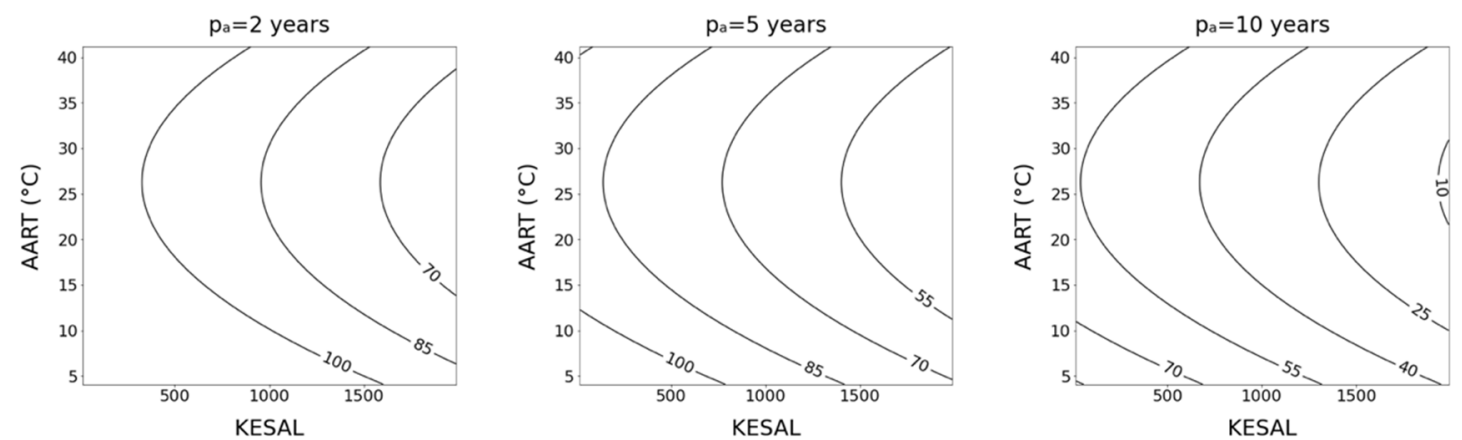

(c)

Figure 9. Combined influence of traffic and weather on pavement condition: (a) Pavement age, KESAL, and AAS; (b) Pavement age, KESAL, and AAT; (c) Pavement age, KESAL, and AART.

\section{Discussion}

Unlike most previous studies on the analysis of pavement deterioration that were developed in a specific region or state and based on single parameters (IRI, cracking, or rutting), this research was carried out using urban pavements located in 17 states and considering the Pavement Condition Index (PCI), which better represents pavement deterioration than single parameters [7,16]. This allowed at identifying the combined influence of pavement structure, traffic, and weather conditions on pavement deterioration process.

Despite the low influence of pavement capacity on the phenomenon, a substantial delay of the deterioration process was observed for Structural Numbers $(S N)$ greater than 10 in. Although further research is needed to obtain firm conclusions, these results suggest that pavements with higher structural capacity have longer a life cycle.

The findings of the study also showed that pavement condition worsened as traffic demand rose and the most influential climatic factors were precipitation and temperature, which were consistent with previous research $[10,11,29-31,36]$. Although these previous studies highlighted the importance 
of rain precipitation, the results of this research revealed that snow precipitation had a greater impact than that in form of rain. Regarding temperature, the most critical variables were found to be the Annual Average Temperature and the Annual Average Range of Temperature, which also showed a great influence on IRI, cracking, rutting, and longitudinal evenness.

An additional analysis was carried out to determine the influence of the climate zones defined by the LTPP program. In this way, the studied pavement sections were classified into the following categories according its precipitation and freezing index: (i) wet-freeze, (ii) wet-non-freeze, (iii) dry-freeze, and (iv) dry-non-freeze. As a result, most of the road sections were located in wet-freeze and wet-non-freeze zones. In this regard, the pavement sections in wet-freeze areas experienced a faster deterioration process than those in wet-non-freeze areas, which was consistent with the results of Perera and Kohn [10].

However, on the basis of the results of this research, a more accurate classification of the climate zones might be defined considering Annual Precipitation, Annual Average Temperature, and Annual Range of Temperature indicated in Table 3. As a result of the combination of these factors, a total of 12 climate areas were proposed.

Table 3. Correlation matrix.

\begin{tabular}{|c|c|c|c|c|c|c|}
\hline \multicolumn{2}{|c|}{ Annual Precipitation } & \multicolumn{3}{|c|}{ Annual Average Temperature } & \multicolumn{2}{|c|}{ Annual Range of Temperature } \\
\hline Wet & Dry & Warm & Cold & Freeze & Stable & Unstable \\
\hline$>800 \mathrm{~mm}$ & $\leq 800 \mathrm{~mm}$ & $>15^{\circ} \mathrm{C}$ & {$[5 ; 15]^{\circ} \mathrm{C}$} & $\leq 5^{\circ} \mathrm{C}$ & $<20^{\circ} \mathrm{C}$ & $\geq 20^{\circ} \mathrm{C}$ \\
\hline
\end{tabular}

Those pavement sections located in wet-freeze zones according to the LTPP program were mainly divided into two new climate areas: wet-cold-unstable (WCU) and dry-freeze-unstable (DFU) zones. Pavements in DFU zones described a delay around two years in the beginning of the deterioration process regarding those in WCU, but the deterioration rate for pavements in DFU zones was substantially greater.

On the other hand, the pavement sections in wet-non-freeze zones according to the LTPP program were mostly classified in wet-warm-stable (WWS) and wet-warm-unstable (WWU) areas. The main difference between both climate zones was that pavement sections in WWU zones presented a faster deterioration process than those in WWS zones.

Table 4 includes different regression models to estimate the PCI in several climatic zones defined in Table 3 (not enough data were available for the other climatic zones). As expected, the accuracy of these models was higher than that obtained without considering climatic areas (Equations (9), (10), and (11)) since grouping the pavement sections into climate zones significantly reduced data variability for each particular climate zone.

Table 4. Correlation matrix.

\begin{tabular}{clc}
\hline Climatic Zone & \multicolumn{1}{c}{ Model } & $\boldsymbol{R}_{\text {test }}^{2}$ \\
\hline WCU & $P C I=243.74-5.55 \cdot p_{a}-0.0164 \cdot K E S A L-30.27 \cdot A A T+1.57 \cdot A A T^{2}$ & 0.62 \\
DFU & $P C I=148.94-10.24 \cdot p_{a}$ & 0.74 \\
WWS & $P C I=217.07-11.34 \cdot p_{a}-0.1474 \cdot K E S A L$ & 0.85 \\
WWU & $P C I=-7.5 \cdot p_{a}+0.0665 \cdot A A P+3.30 \cdot A A T$ & 0.85 \\
\hline
\end{tabular}

The calibrated models for these specific climatic zones are consistent with the regression analysis developed in this study. The models related to WWS and WWU zones revealed the importance of the stability of the temperature on pavement deterioration process. Whereas the pavement condition under weather unstable conditions depended on the annual average of precipitation and temperature (WCU and WWU), the influence of these variables on pavements located in WWS zones was negligible. In addition, the comparison between the models associated with WCU and DFU zones showed the 
influence of precipitation under low and unstable temperatures. While the traffic demand played an important role in both wet and dry environments, the annual average temperature was only significant in wet areas. As mentioned previously, this can be explained through the great influence of temperature on freeze-thaw phenomenon, which has a great impact on pavement deterioration.

Although the definition of climate zones can ease the analysis of pavement deterioration, it is well-known that the climate conditions in a certain region (state or country) are changing every day because of climate change. Moreover, small regions in a specific state or country might be characterized by very different climate conditions (e.g., North Carolina). Therefore, the development of pavement prediction models without taking into account climate factors might not be useful in midand long-term.

\section{Conclusions and Further Research}

Most previous research on the analysis of pavement deterioration has been focused on the individual influence of traffic or weather on pavement condition. Thus, the main objective of this study was to determine the individual and combined influence of pavement structure, traffic demand, and climate factors on pavement condition over time. To do this, the Structural Number (SN), diverse traffic and climate variables, and the Pavement Condition Index (PCI) were estimated for a total of 237 pavement assessments performed in 53 urban road sections consisting of flexible pavements.

The most influential traffic variable on pavement deterioration process was the Equivalent Single Axle Load in thousands (KESAL), which was able to better represent traffic demand than AADT or $A A D T T$. For a given pavement age, pavement condition worsened as KESAL increased. Particularly, the PCI decreased over 3 units per 100,000 Equivalent Single Axle Load.

On the other hand, precipitation and temperature were found to be the most important weather factors affecting pavement condition. In this regard, for a given pavement age, pavement condition was poorer as the annual height of snow increased. Likewise, a cold annual average temperature $\left(5-15^{\circ} \mathrm{C}\right)$ and a large annual range of temperature $\left(20-30^{\circ} \mathrm{C}\right)$ encouraged a sudden and more aggressive pavement deterioration process.

Although further research is needed to obtain definite conclusions regarding the influence of the pavement composition on pavement deterioration process, the findings of this study point out that the life cycle of a pavement section increases as its structural capacity is greater.

The combined analysis verified the findings obtained from the individual analysis. As a conclusion, faster pavement deterioration is expected as traffic demand and annual height of snow increase. In addition, warm climates with low temperature variations, which are associated with low precipitation, lead to a longer pavement service life.

Finally, a new classification of climate zones was proposed on the basis of the weather influence on pavement deterioration. Additionally, various regression models were calibrated for several climate zones which validated the critical role of traffic demand, precipitation, and temperature in pavement condition.

Therefore, the findings of this research are crucial so as to predict pavement condition on urban pavements and, consequently, anticipate and prioritize the maintenance and rehabilitation activities. Given that most highway administrations are carrying out a reactive maintenance of the urban road network, this research will allow them to anticipate the future pavement condition and perform a proactive urban road maintenance. In this way, the greenhouse gases emissions related to road maintenance and rehabilitation activities as well as those associated with the vehicles driving along the urban road network will be minimized. Likewise, a good condition of an urban road pavement will allow its users to reduce fuel consumption and increase their comfort.

However, the conclusions of this study are limited to flexible pavements located in urban collectors and arterials. Further research is needed to analyze the influence of traffic and weather on pavement condition of rural roads and urban local roads such as city streets. Regarding this, data form other climatic zones should be gathered to extend the conclusions of this research. Moreover, the performance 
of other pavement condition parameters, such as the Single and Combined Performance Indexes (PIs) and the Urban Pavement Condition Index (UPCI), are proposed to be studied to check the validity of the findings of this study.

Author Contributions: Conceptualization, D.L.-C., T.G.-S., and L.M.-D.; methodology, D.L.-C., T.G.-S., and L.M.-D.; data collection and reduction, D.L.-C.; formal analysis, D.L.-C., T.G.-S., L.M.-D., E.P., and A.S.-B.; writing-original draft preparation, D.L.-C.; writing-review and editing, T.G.-S., L.M.-D., E.P., and A.S.-B.; supervision, E.P. All authors have read and agreed to the published version of the manuscript.

Funding: This research was funded by the Spanish Ministry of Science and Innovation, grant number RTC-2017-6148-7, with the European Regional Development Fund.

Conflicts of Interest: The authors declare no conflict of interest. The funders had no role in the design of the study, in the collection, analyses, or interpretation of data, in the writing of the manuscript, or in the decision to publish the results.

\section{References}

1. Bull, A. Traffic Congestion: The Problem and How to Deal with It; (No. 87); United Nations Publications: New York, NY, USA, 2003.

2. Hajj, E.Y.; Loria, L.; Sebaaly, P.E. Performance evaluation of asphalt pavement preservation activities. Transp. Res. Rec. 2010, 2150, 36-46. [CrossRef]

3. Santero, N.J.; Horvath, A. Global warming potential of pavements. Environ. Res. Lett. 2009, 4, 034011. [CrossRef]

4. Pérez-Acebo, H.; Linares-Unamunzaga, A.; Abejón, R.; Rojí, E. Research trends in pavement management during the first years of the 21st century: A bibliometric analysis during the 2000-2013 period. Appl. Sci. 2018, 8, 1041. [CrossRef]

5. Prozzi, J.A.; Madanat, S.M. Development of pavement performance models by combining experimental and field data. J. Infrastruct. Syst. 2004, 10, 9-22. [CrossRef]

6. Ragnoli, A.; De Blasiis, M.R.; Di Benedetto, A. Pavement distress detection methods: A review. Infrastructures 2018, 3, 58. [CrossRef]

7. Osorio, A.; Chamorro, A.; Tighe, S.; Videla, C. Calibration and validation of condition indicator for managing urban pavement networks. Transp. Res. Rec. 2014, 2455, 28-36. [CrossRef]

8. Cantisani, G.; Pantuso, A.; Mascio, P. Sustainable pavement management system in urban areas considering the vehicle operating costs. Sustainability 2017, 9, 453. [CrossRef]

9. Miller, J.S.; Bellinger, W.Y. Distress Identification Manual for the Long-Term Pavement Performance Project; Publication No. FHWA-RD-03-031; Federal Highway Administration, United States Department of Transportation: Washington, DC, USA, 2003.

10. Perera, R.W.; Kohn, S.D. LTPP Data Analysis: Factors Affecting Pavement Smoothness. NCHRP Web Document 40. 2001. Available online: http://onlinepubs.trb.org/onlinepubs/nchrp/nchrp_w40-a.pdf (accessed on 9 November 2019).

11. Madanat, S.M.; El Nakat, Z.; Sathaye, N. Development of Empirical-Mechanistic Pavement Performance Models Using Data from the Washington State PMS Database; Research Rep. UCPRC-RR-2005-05; University of California: Davis, CA, USA; Pavement Research Center: Davis, CA, USA, 2005.

12. Arambula, E.; George, R.; Xiong, W.; Hall, G. Development and validation of pavement performance models for the state of Maryland. Transp. Res. Rec. 2011, 2225, 25-31. [CrossRef]

13. Meegoda, J.N.; Gao, S. Roughness progression model for asphalt pavements using long-term pavement performance data. J. Transp. Eng. 2014, 140, 830-843. [CrossRef]

14. Pérez-Acebo, H.; Mindra, N.; Railean, A.; Rojí, E. Rigid pavement performance models by means of Markov Chains with half-year step time. Int. J. Pavement Eng. 2019, 20, 830-843. [CrossRef]

15. Shafizadeh, K.; Mannering, F. Acceptability of pavement roughness on urban highways by driving public. Transp. Res. Rec. 2003, 1860, 187-193. [CrossRef]

16. American Society for Testing and Materials (ASTM). Standard Practice for Roads and Parking Lots Pavement Condition Index Surveys; (No. ASTM D6433-11); American Society for Testing and Materials (ASTM): West Conshohocken, PA, USA, 2003. 
17. American Association of State Highway and Transportation Officials (AASHTO). Pavement Management Guide; American Association of State Highway and Transportation Officials (AASHTO): Washington, DC, USA, 2001.

18. Litzka, J.; Leben, B.; Torre, F.L.; Weninger-Vycudil, A.; Antunes, M.L.; Kokot, D.; Mladenović, G.; Brittain, S.; Viner, H. The Way Forward for Pavement Performance Indicators Across Europe. COST Action 354: Performance Indicators for Road Pavements; European Cooperation in Science and Technology: Brussels, Belgium, 2008.

19. Osorio-Lird, A.; Chamorro, A.; Videla, C.; Tighe, S.; Torres-Machi, C. Application of Markov chains and Monte Carlo simulations for developing pavement performance models for urban network management. Struct. Infrastruct. Eng. 2018, 14, 1169-1181. [CrossRef]

20. Pérez-Acebo, H.; Gonzalo-Orden, H.; Findley, D.J.; Rojí, E. A skid resistance prediction model for an entire road network. Constr. Build. Mater. 2020, 262, 120041. [CrossRef]

21. Pérez-Acebo, H.; Linares-Unamunzaga, A.; Rojí, E.; Gonzalo-Orden, H. IRI Performance Models for Flexible Pavements in Two-Lane Roads until First Maintenance and/or Rehabilitation Work. Coatings 2020, 10, 97. [CrossRef]

22. Dong, Q.; Huang, B.; Richards, S.H. Calibration and Application of Treatment Performance Models in a Pavement Management System in Tennessee. J. Transp. Eng. 2015, 141, 04014076. [CrossRef]

23. Hassan, R.; Lin, O.; Thananjeyan, A. A comparison between three approaches for modelling deterioration of five pavement surfaces. Int. J. Pavement Eng. 2017, 18, 26-35. [CrossRef]

24. Pérez-Acebo, H.; Gonzalo-Orden, H.; Rojí, E. Skid resistance prediction for new two-lane roads. Proc. Inst. Civ. Eng. Transp. 2019, 172, 264-273. [CrossRef]

25. Ziari, H.; Maghrebi, M.; Ayoubinejad, J.; Waller, T. Prediction of Pavement Performance: Application of Support Vector Regression with Different Kernels. Transp. Res. Rec. 2016, 2589, 135-145. [CrossRef]

26. Moreira, A.V.; Tinoco, J.; Oliveira, J.R.M.; Santos, A. An application of Markov chains to predict the evolution of performance indicators based on pavement historical data. Int. J. Pavement Eng. 2018, 19, 937-948. [CrossRef]

27. Pérez-Acebo, H.; Bejan, S.; Gonzalo-Orden, H. Transition probability matrices for flexible pavement deterioration models with half-year cycle time. Int. J. Civ. Eng. 2018, 16, 1045-1056. [CrossRef]

28. García-Segura, T.; Montalbán-Domingo, L.; Llopis-Castelló, D.; Lepech, M.D.; Sanz, M.A.; Pellicer, E. Incorporating pavement deterioration uncertainty into pavement management optimization. Int. J. Pavement Eng. 2020, 1-12. [CrossRef]

29. Qiao, Y.; Flintsch, G.W.; Dawson, A.R.; Parry, T. Examining effects of climatic factors on flexible pavement performance and service life. Transp. Res. Rec. 2013, 2349, 100-107. [CrossRef]

30. Hasan, M.R.M.; Hiller, J.E.; You, Z. Effects of mean annual temperature and mean annual precipitation on the performance of flexible pavement using ME design. Int. J. Pavement Eng. 2016, 17, 647-658. [CrossRef]

31. Anastasopoulos, P.C.; Mannering, F.L. Analysis of pavement overlay and replacement performance using random parameters hazard-based duration models. J. Infrastruct. Syst. 2015, 21, 04014024. [CrossRef]

32. Alaswadko, N.; Hassan, R. Rutting progression models for light duty pavements. Int. J. Pavement Eng. 2016, 19, 37-47. [CrossRef]

33. El-Raof, H.S.A.; El-Hakim, R.T.A.; El-Badawy, S.; Afify, H.A. Structural number prediction for flexible pavements using the long term pavement performance data. Int. J. Pavement Eng. 2018, 21, 841-855. [CrossRef]

34. Rohde, G.T. Determining pavement structural number from FWD testing. In Transportation Research Record; Transportation Research Board: Washington, DC, USA, 1994; p. 1448.

35. American Association of State Highway and Transportation Officials (AASHTO). Guide for Design of Pavement Structures; American Association of State Highway and Transportation Officials (AASHTO): Washington, DC, USA, 1993.

36. Adlinge, S.S.; Gupta, A.K. Pavement deterioration and its causes. Int. J. Innov. Res. Dev. 2013, 2, 437-450.

37. Almeida, A.; Moreira, J.J.; Silva, J.P.; Viteri, C.G. Impact of traffic loads on flexible pavements considering Ecuador's traffic and pavement condition. Int. J. Pavement Eng. 2019, 1-8. [CrossRef]

38. Berrar, D. Cross-validation. In Encyclopedia of Bioinformatics and Computational Biology; Elsevier Science: Amsterdam, The Netherlands, 2019; pp. 542-545. 
39. Simon, R. Resampling strategies for model assessment and selection. In Fundamentals of Data Mining in Genomics and Proteomics; Springer: Boston, MA, USA, 2007; pp. 173-186.

Publisher's Note: MDPI stays neutral with regard to jurisdictional claims in published maps and institutional affiliations.

(C) 2020 by the authors. Licensee MDPI, Basel, Switzerland. This article is an open access article distributed under the terms and conditions of the Creative Commons Attribution (CC BY) license (http://creativecommons.org/licenses/by/4.0/). 